\title{
Effect of gestational zinc deficiency on pregnancy outcomes: summary of observation studies and zinc supplementation trials
}

\author{
Dheeraj Shah and H. P. S Sachdev* \\ Division of Clinical Epidemiology, Department of Pediatrics, Maulana Azad Medical College, New Delhi 110 002, India
}

\begin{abstract}
The lack of a valid indicator precludes a true estimate of zinc deficiency in pregnancy in various populations. However, it is possible that mild to moderate deficiency (as assessed by available indicators) may be common in the developing world. Animal experiments indicate that zinc deficiency can result in adverse maternal and fetal consequences. Human data, particularly from prenatal zinc supplementation trials, has failed to document a consistent maternal or infant benefit on evaluated outcome measures including pregnancy induced hypertension, preterm/ post-term labour, premature rupture of membranes, maternal infection, postpartum haemorrhage, perinatal mortality, congenital malformations and fetal growth and gestation. Preliminary data suggest a beneficial effect of prenatal zinc supplementation on infants' neurobehavioural development and immune function (evaluated by diarrhoeal and ARI morbidity incidence in the first year of life). Future research should focus on these functional consequences and congenital malformations (with adequate sample sizes), and simultaneously address the safety issue, particularly in relation to micronutrient interactions. In the light of the currently available information, routine zinc supplementation can not be advocated to improve pregnancy outcome.
\end{abstract}

Pregnancy outcome: Review: Zinc supplementation

Zinc plays a critical role in normal growth and development, cellular integrity and many biological functions, including protein synthesis and nucleic acid metabolism (Vallee \& Falchuk, 1993). It is present in more than seventy metalloenzymes including RNA polymerase and thymidine kinase. Since all these are involved in cell division and growth, zinc is believed to be important for fetal growth and development. This review examines the possibility that a gestational deficiency of zinc can adversely affect the pregnancy outcome.

\section{Magnitude of the problem}

There is scant reliable information regarding the magnitude of zinc deficiency in pregnant women, largely because of lack of consensus on appropriate indicators of zinc status in the pregnant state. Although severe zinc deficiency is rare, it is estimated that mild to moderate zinc deficiency might be common in several regions of the world. However, in the absence of a valid marker for zinc deficiency, there is no direct evidence for this estimate.

Zinc nutriture, most commonly assessed by plasma zinc concentrations, in pregnant women is different from that in the non-pregnant state. Plasma zinc concentration begins to decline in early pregnancy and continues to decline till term, when it is about $35 \%$ below the concentration found in non pregnant women (Zimmerman et al. 1984; Tamura \& Goldenberg, 1996). There are discrepancies concerning the rate of decline, which may reflect the varying zinc status among the women studied. The decline in the zinc levels has been attributed to haemodilution, decrease in levels of zinc binding protein, hormonal changes during pregnancy (Jameson, 1976) and active transport of zinc from the mother to the fetus (Tamura \& Goldenberg, 1996). All these factors diminish the validity of serum zinc as an indicator of zinc nutriture in pregnancy.

Dietary zinc intake in pregnant women has also been used as an indicator of deficiency. Tamura \& Goldenberg (1996) reported mean dietary zinc intakes in pregnant nonvegetarians to be around $10.0 \mathrm{mg} /$ day in 27 studies from various parts of the world, against the US Recommended Dietary Allowance (RDA) of $16 \mathrm{mg} /$ day (National Research Council, 1989). Most of these studies were conducted in the US and UK. The intake by vegetarians in developing countries is usually much lower (CampbellBrown et al. 1985; Lehti, 1989; Kirskey et al. 1994). Caulfield et al. (1998) have estimated by probability method that $82 \%$ of the pregnant women world-wide are likely to have inadequate intakes of zinc. These estimates were derived from the usual intakes reported in the literature (Parr, 1996) and the estimated distribution of zinc required by women to meet their normative needs during pregnancy as per USRDA. This derivation is a crude estimate since the estimated requirement distribution is based on higher body weights and greater usual intakes of zinc in pregnant women from developed countries. The

\footnotetext{
* Corresponding author: Dr H. P. S. Sachdev, email jiap@ren.nic.in.
} 
need to modify the present recommended intakes of zinc has been raised before (Ortega et al. 1997), as a lower intake might not be necessarily associated with lower levels in serum or an adverse pregnancy outcome.

Since the currently available methods do not provide a reliable estimate of the magnitude of the deficiency, it has been suggested that supplementation trials should be relied upon to define the extent of maternal zinc deficiency. However, the currently available supplementation studies in the literature are too inadequate to permit any such estimation.

\section{Maternal consequences of zinc deficiency}

Animal experiments indicate that maternal zinc deficiency upsets both the sequencing and efficiency of parturition. An increased incidence of difficult and prolonged labour, haemorrhage, uterine dystocia and placental abruption has been documented in female rats fed zinc deficient diets throughout pregnancy (Apgar, 1968). A beneficial effect of zinc supplementation in zinc deficient rats has also been documented (Apgar, 1973). These observations have been confirmed in zinc deficient rhesus monkeys (Golub et al. $1984 b$ ). The effects are possibly mediated by the defective functioning of oestrogen via the oestrogen receptor, which contains a zinc-finger protein (Bunce et al. 1994). The dysfunction of oestrogen impairs uterine contractions, cervical ripening and dilatation, maintenance of fetal membrane and amniotic fluid integrity (Cunnane, 1982; Olson et al. 1995).

Observational studies in humans have inconsistently observed association of low maternal serum zinc concentrations during pregnancy or at delivery with pregnancy induced hypertension, prolonged rupture of membranes, abruptio placentae, inefficient uterine contractions, prolonged or non-progressive labour, and maternal haemorrhage and infections. Low maternal zinc status during pregnancy or delivery has been shown to be associated with a 3.5-7 fold increased risk for premature rupture of membranes (Sikorski et al. 1990; Scholl et al. 1993); while others (Kiilholma et al. 1984) have found no such association. Similarly, associations have been observed with placental abruption (Kynast \& Saling, 1986), prolonged first and second stage of labour (Dura-Trave et al. 1984; Lazebnik et al. 1988), perineal tears (Lazebnik et al. 1988) and pregnancy induced hypertension (Cherry et al. 1981; Lazebnik et al. 1988). Conversely, other authors failed to document such associations (Prema, 1980; Dreosti \& MacLennan, 1990; Lao et al. 1990). In the most recent investigation admitting the largest number of subjects (Tamura et al. 2000), no significant association was found between plasma zinc concentrations and maternal complications including preterm delivery, hypertension, amnionitis and postpartum infection.

Studies to evaluate the effect of zinc supplementation on pregnancy related complications have provided mixed results. A Cochrane systematic review of five supplementation trials (Mahomed, 1998) did not document a significant beneficial effect apart from possible reduction in induction of labour (OR $0.18 ; 95 \%$ CI 0.06 to 0.57 , derived from a single trial). The studies included normal pregnant women who were supplemented with $20-62 \mathrm{mg}$ of elemental zinc (with or without placebo controls) from at least 26 weeks of gestation. Out of these, two trials (Hunt et al. 1983, 1985) selected women at high risk of low zinc status and in one study (Goldenberg et al. 1995), the participants were selected on the basis of proven low plasma zinc levels. Three studies were excluded mainly because of high $(25 \%)$ loss of subjects recruited initially. In this investigation, routine zinc supplementation in pregnancy had no detectable effects on any of the clinical measures of pregnancy outcome namely; pregnancy induced hypertension, preterm/post-term labour, premature rupture of membranes, maternal infection, postpartum haemorrhage or perinatal mortality. Another study (Jonsson et al. 1996), not included in the Cochrane review, also did not find any benefit of zinc supplementation on preeclampsia or bleeding in the second or third trimester.

To summarise, there is no conclusive evidence of substantial benefit to recommend routine zinc supplementation during pregnancy to prevent labour and delivery complications.

\section{Consequences for the progeny}

Zinc is essential for the normal growth and development of the fetus. Severe maternal zinc deficiency, as seen in acrodermatitis enteropathica, has been associated with spontaneous abortion and congenital malformations (Hambidge et al. 1975), whereas milder forms have been associated with low birth weight, intrauterine growth retardation and preterm delivery (Jameson, 1993).

\section{Congenital malformations}

Hurley \& Swenerton (1966) documented a teratogenic effect of zinc deficiency in pregnant rats, in particular of the central nervous system. Since then, numerous studies have confirmed the important anti-teratogenic role of zinc in animals. Recent experimental data indicate that even in zinc sufficient or borderline deficient animals, stressful events like infection can result in sequestration of body zinc making it unavailable for the growing fetus. If this happens during a critical period of organ development, the 'sequestration induced deficiency' can prove teratogenic for the fetus (Keen et al. 1993).

Epidemiological data (Halsted, 1973; Sever, 1973) and case reports (Hambidge et al. 1975; Cavdar et al. 1991) in humans support the experimental observations that severe zinc deficiency can cause fetal malformations which can be reversed by supplementation with oral zinc. Hambidge et al. (1975) reviewed the pregnancy outcomes in women with acrodermatitis enteropathica and reported that out of seven pregnancies, there was one abortion and two malformations, suggesting that the human fetus is also susceptible to the teratogenic effect of severe zinc deficiency. Thereafter, Brenton et al. (1981) suggested that treating the mothers with zinc antenatally could prevent these malformations.

There are very few well-controlled studies in humans that have evaluated a possible causal relationship between zinc deficiency and fetal malformations. Most of the data in 
Table 1. Summary of zinc supplementation trials on fetal growth

\begin{tabular}{|c|c|c|c|c|}
\hline Investigators & Study place & $\begin{array}{l}\text { Total number } \\
\text { of subjects (zinc } \\
\text { supplemented/ } \\
\text { control) }\end{array}$ & $\begin{array}{l}\text { Dose of } \\
\text { elemental zinc } \\
\text { (mg/day) }\end{array}$ & Major outcomes in terms of fetal growth \\
\hline Hunt et al. (1984) & USA & $\begin{array}{l}213 \\
107 / 106\end{array}$ & 20 & No difference in birth weight, low birth weight or preterm \\
\hline Hunt et al. (1985) & USA & $\begin{array}{l}138 \\
70 / 68\end{array}$ & 20 & No difference in birth weight \\
\hline Ross et al. (1985) & South Africa & $\begin{array}{l}65 \\
32 / 33\end{array}$ & $4 \cdot 3-12 \cdot 9$ & No difference in birth weight \\
\hline Kynast \& Saling (1986) & Germany & $\begin{array}{l}524 \\
170 / 345\end{array}$ & 20 & $\begin{array}{l}\text { Increase of } 82 \mathrm{~g} \text { birth weight but not statistically significant } \\
\text { Significant difference in LGA, SGA and preterm }\end{array}$ \\
\hline Cherry et al. (1989) & USA & $\begin{array}{l}556 \\
268 / 288\end{array}$ & 30 & $\begin{array}{l}\text { No difference in birth weight } \\
\text { Reduced rate of prematurity }\end{array}$ \\
\hline Mahomed et al. (1989) & UK & $\begin{array}{l}494 \\
246 / 248\end{array}$ & 20 & No difference in birth weight or SGA \\
\hline Robertson et al. (1991) & UK & $\begin{array}{l}134 \\
72 / 62\end{array}$ & 62 & $\begin{array}{l}\text { No difference in birth weight, low birth weight, high birth } \\
\text { weight, LGA or SGA }\end{array}$ \\
\hline Simmer et al. (1991) & UK & $\begin{array}{l}56 \\
30 / 26\end{array}$ & $22 \cdot 5$ & $\begin{array}{l}\text { Increase of } 170 \mathrm{~g} \text { in birth weight but not significant } \\
\text { Significant decrease in SGA }\end{array}$ \\
\hline Garg et al. (1993) & India & $\begin{array}{l}280 \\
90 / 190\end{array}$ & 45 & Significant $(300-800 \mathrm{~g})$ difference in birth weight \\
\hline Goldenberg et al. (1995) & USA & $\begin{array}{l}580 \\
294 / 286\end{array}$ & 25 & $\begin{array}{l}\text { Significant benefit in birth weight }(126 \mathrm{~g} ; \mathrm{P}=0.03) \text {, low birth } \\
\text { weight and head circumference }(0.4 \mathrm{~cm} ; P=0.02) \\
\text { No difference in small for gestational age or preterm }\end{array}$ \\
\hline Jonsson et al. (1996) & Denmark & $\begin{array}{l}1206 \\
585 / 621\end{array}$ & 44 & No difference in birth weight, LGA, SGA, or preterm \\
\hline Caulfield et al. (1999b) & Peru & $\begin{array}{l}1016 \\
521 / 495\end{array}$ & 15 & $\begin{array}{l}\text { No difference in duration of pregnancy, birth weight, preterm } \\
\text { or post-term delivery, low birth weight or high birth weight, } \\
\text { head circumference, chest circumference, crown-heel } \\
\text { length, mid-upper arm circumference and skin-fold thickness }\end{array}$ \\
\hline Osendarp et al. (2000) & Bangladesh & $\begin{array}{l}559 \\
269 / 290\end{array}$ & 30 & $\begin{array}{l}\text { No difference in birth weight, low birth weight, preterm, SGA, } \\
\text { infant length, head, chest or mid-arm circumference }\end{array}$ \\
\hline
\end{tabular}

this context is retrospective and has produced mixed results. In the largest and most recent of such investigations (Velie et al. 1999), 430 neural tube disease affected fetuses and infants were compared with 429 normal controls. Maternal intake of pre conceptional vitamins, minerals and food supplements was recorded. The authors reported a reduced risk of neural tube defects with increased total pre conceptional zinc intake (OR 0.65; $95 \%$ CI $0.43,0.99$ ). These benefits were independent of the other confounding variables such as folate intake and sociodemographic factors. However, the data is to be interpreted with caution as zinc nutriture in this study was assessed by recall method and it remains unclear whether increased zinc intake, or another nutrient or combination of nutrients highly correlated with zinc intake in the diet, is causally associated with reduced risk of neural tube defects. In another recent, prospective case-control study (Stoll et al. 1999), no difference was found in maternal plasma zinc concentration at the beginning of pregnancy in 170 malformed newborns as compared to controls.

The supplementation trials have failed to show a significant benefit of zinc supplementation in reducing congenital malformations. In a Cochrane review of supplementation trials (Mahomed, 1998), six out of 350 babies in the supplemented group and ten out of 333 in the control group had congenital malformations (OR 0.56; $95 \%$ CI $0 \cdot 21,1 \cdot 53)$. However, it would be prudent to state that this meta-analysis does not have a sufficient sample size to reliably assess the effect on congenital malformations.

Based on the data available to date, a definite conclusion cannot be drawn as to whether the deficiency of zinc alone during pregnancy is teratogenic in humans. The studies are mostly retrospective and have not been well controlled. Further, no reliable method of estimating mild to moderate zinc deficiency in pregnant women is available. Thus, the issue of preventing fetal malformations with zinc supplementation remains unsolved.

\section{Fetal growth and duration of gestation}

Many studies have been reported on the association between maternal zinc nutriture and birth weight of babies, both in animal and human populations. There is no consensus in the literature as to whether maternal zinc nutriture is associated with fetal growth in humans. Of 46 studies reporting an association between maternal plasma, serum or leucocyte zinc concentration and fetal growth (expressed either as average birth weight or proportions with low birth weight such as below the tenth percentile), twenty-three $(50 \%)$ reported a positive relationship; however the other half found no such relation (Tamura \& Goldenberg, 1996; Biadaioli et al. 1997; Tamura et al. 1997; George et al. 1998; Roungsipragarn et al. 1999; Tamura et al. 2000). In the largest of such investigations, conducted on 3448 pregnant women, no significant 
association was documented between plasma zinc concentration and fetal growth including birth weight, prematurity, head circumference and crown-heel length (Tamura et al. 2000). Of the eighteen studies from developing countries' populations, ten had a positive relationship. This lack of agreement may be due to differences in timing of sampling, laboratory methods and quality, sample size and underlying zinc nutriture of the populations (Caulfield et al. 1998).

The results of thirteen zinc supplementation trials (Table 1) have not shown a consistent significant improvement in weight, length or head circumference at birth or a reduction in small for gestational age infants. Most of these trials were from well-nourished populations in developed countries and thus did not address the basic issue of improvement in fetal growth in zinc deficient populations. Only four studies have been conducted on poor women of developing countries. Ross et al. (1985) studied pregnancy outcomes in sixty-five Zulu women in South Africa and reported no significant difference in birth weight between zinc supplemented and control groups. However, in this study, the intervention and control population were not comparable as the mothers in the treatment group weighed considerably less than those in the control group at 20 weeks of gestation. Garg et al. (1993) observed a 300-800 g difference in birth weight in 106 Indian mothers who were supplemented with $45 \mathrm{mg}$ elemental zinc/day compared with sixty unsupplemented controls. In this poorly controlled study, the sample size was small, and there was high loss to follow up at the final analysis, thus making it difficult to draw conclusions. Caulfield et al. (1999b) enrolled 1295 pregnant mothers with low zinc status in Lima, Peru in a placebo controlled zinc supplementation trial and found no differences in duration of pregnancy $(39.4 \pm 2.2$ v. $39.5 \pm 2.0$ weeks), birth weight $(3267 \pm 461$ v. $3300 \pm 498 \mathrm{~g})$, preterm and low birth weight between supplemented and control groups. In the same population, it was found (Caulfield et al. 1999a) that although mothers receiving zinc supplementation had higher serum zinc concentration than controls, the maternal zinc concentrations remained lower than values reported for well nourished populations. It was concluded that higher doses of zinc might be needed to further improve the maternal zinc status in this population.

Osendarp et al. (2000) conducted a double blind placebocontrolled trial in 559 malnourished Bangladeshi women from Dhaka slums, who were randomised to receive 30-mg elemental zinc/day or placebo. They also showed that although serum concentrations tended to be higher in the zinc-supplemented group than in the placebo group, no significant effect of treatment was evident on infant birth weight, gestational age, length or head, chest and mid upper arm circumferences. The study was conducted in a malnourished population in which the dietary zinc intake was low and poorly bioavailable and the dosage used was twice the recommended dietary zinc intake for pregnant women.

In the 1998 Cochrane systematic review (Mahomed, 1998) of five published methodologically sound randomised controlled trials, zinc supplementation had no significant effect on preterm delivery, small for dates, low birth weight or any other measure of growth. However, low birth weight, small for gestational age and preterm delivery all appeared to be individually significant in trials that had selected women with, or at high risk of, low zinc status. Overall, there were some differences that were in the direction of benefit for zinc supplementation: preterm delivery, small for gestational age and low birth weight; but these did not exhibit statistical significance. It was suggested that trials of zinc supplementation should be conducted in regions of the world where an overall deficiency of zinc is expected. Since the publication of this review, the results of at least three other trials (Jonsson et al. 1996; Caulfield et al. 1999b; Osendarp et al. 2000) have become available (two from developing countries); all of which have failed to show a significant or even marginal benefit of zinc supplementation in terms of fetal growth. The completion of other ongoing trials in developing countries is eagerly awaited.

In summary, the currently available evidence does not support a beneficial effect of maternal zinc supplementation on fetal growth and gestation.

\section{Postnatal growth}

Experiments in rhesus monkeys suggest that growth faltering associated with maternal zinc deficiency during fetal life lasts throughout infancy (Golub et al. 1984a). There is no published data available to document a long lasting effect of maternal zinc deficiency on infant growth or the benefit of antenatal zinc supplementation to the postnatal growth in humans. It would be interesting to document the extent and duration of postnatal benefits to the infant, if any, in terms of growth independent of the other factors like reduced morbidity through improved immune functions.

\section{Neurobehaviour development}

The relationship between zinc deficiency and delayed development of brain functions has been firmly established in animals (Sandstead, 1985; Tamura \& Goldenberg, 1996). Zinc is a critical nutrient for central nervous system development through zinc-dependent enzymes, zinc finger proteins which are required for neurotransmission and zincdependent neurotransmitters in the mossy fibres of the hippocampus (Dreosti et al. 1981; Howell et al. 1984; Frederickson \& Danscher, 1990). Besides that, zinc also seems to be involved in metabolism of thyroid hormones (Morley et al. 1980), hormone transport, receptor binding and metabolism and neurotransmitting precursor production (Golub et al. 1995); all of which ultimately affect CNS function.

As the intrauterine period is critical for brain growth in infants, maternal zinc deficiency could cause adverse effects on fetal and infant neurological and behavioural development. There is some animal data to support this hypothesis. Apgar (1968) reported apathy among zincdeficient dams at parturition. Golub et al. (1984a,b, 1985, $1988,1992,1995)$ in a series of experiments on rhesus monkeys demonstrated that maternal and infant zinc deficiency had an adverse outcome on fetal activity 
pattern, newborn motor development and behaviour patterns during infancy and adolescence.

Observational data in humans linking the effect of prenatal zinc deficiency on neurodevelopmental changes in children is scarce. Kirksey et al. (1991) reported a significant positive association between maternal intake of dietary zinc and neonatal habituation behaviour in a small village in Egypt. Subsequently, in the same location, they documented the persistence of positive association between maternal zinc status during pregnancy and infant developmental profile at six months of age (Kirskey et al. 1994).

Fetal heart rate $(n=55)$ and movement patterns $(n=$ 34) were evaluated, as indices of neurobehavioural development (Merialdi et al. 1999), in a subset of the Peruvian zinc supplementation trial (Caulfield et al. $1999 b$ ). Fetuses of mothers who received zinc supplementation showed fewer episodes of minimal fetal heart rate (FHR) variability, increased FHR range, an increased number of accelerations, an increased number of movement bouts, an increased number of time spent moving, and an increased number of large movements. The authors concluded that improving maternal zinc status through prenatal supplementation might improve fetal neurobehavioural development. However, the surrogate measures employed to assess neurobehavioural development need validation. The results of postnatal follow up of this study and another zinc supplementation trial, which documented an increase in head circumference of infants at birth (Goldenberg et al. 1995), are awaited with interest.

Preliminary data suggests a role of maternal zinc status in the neurobehavioural development of the infant. However, caution must be exercised before drawing definite conclusions because of the inherent problems of controlling for confounders in such studies. More well controlled supplementation trials in zinc deficient populations are needed to demonstrate the beneficial effect on motor and cognitive development.

\section{Infection and immunity}

The immune system is particularly sensitive to perturbation in zinc status. Thymus, spleen, lymph nodes and Peyer's patches develop hypoplasia depending upon the severity and duration of zinc deficiency (Miller et al. 1968; Chandra \& Au, 1980; Seth \& Beotra, 1986). Decreased lymphocyte population with special reference to reduced function of helper T-lymphocytes and natural killer cells with increase in B-cells have been demonstrated (Miller et al. 1968; Chandra \& Au, 1980; Seth \& Beotra, 1986). Perinatal zinc deficiency can result in poor development of natural immunity and decreased acquisition of maternal antibodies (Shankar \& Prasad, 1998). Perinatal zinc deficiency results in decreased spleen and thymus size, impaired lymphocyte mitogenic responses and plaque forming activity, and depressed immunoglobulin concentrations (Beach et al. $1982 b$ ). The adverse effect on the immune system might even be permanent, persisting after restoration of normal dietary zinc intake (Beach et al. 1982a, b, 1983).

The effect of perinatal zinc deficiency on the immune status of infants has not been studied adequately in humans.
In a supplementation trial designed to evaluate the effect of antenatal zinc supplementation on pregnancy outcome (Goldenberg et al. 1995); no beneficial effect of zinc supplementation was observed in decreasing neonatal sepsis (1/294 in supplemented v. 5/286 in controls; OR $0 \cdot 25 ; 95 \%$ CI $0 \cdot 05,1 \cdot 26)$. However, this trial was mainly designed to evaluate the effect on other measures like birth weight and a sample size for a precise evaluation of the benefit in terms of neonatal sepsis was inadequate. The effect of maternal zinc supplementation in reducing the incidence of diarrhoea and potential ARI mortality in infants throughout the first year of life is under investigation. Preliminary data indicates a reduction in diarrhoeal and respiratory morbidity (incidence) in infants throughout the first year of life with prenatal zinc supplements, which were not continued after birth (Caulfield, 1999, Personal communication). This benefit may be due to the impact of zinc supplementation on ontogeny of immunological development in the infant during the first year of life.

More research is needed to document the influence of perinatal zinc deficiency on immunity and subsequent risk of infection related morbidity in infants.

\section{Potential adverse effects}

Before recommending routine supplementation with a micronutrient, it is essential to thoroughly address its safety. This includes consequences of interaction with other important micronutrients and vitamins. Fluctuation in the status of one micronutrient may alter the metabolism of another with functional consequences on the health of the individual. Seemingly minute changes in this context may assume practical significance in populations with borderline nutriture as in the developing countries. Zinc can have possible interactions with iron (Whittaker, 1998), copper (Garg et al. 1994; Sandstrom et al. 1994) and vitamin A (Christian \& West, 1998).

Unfortunately, the earlier supplementation trials were not designed to address this important aspect. Future research must give due importance to the safety issue, particularly on a subclinical scale.

\section{Conclusions}

The lack of a valid indicator precludes a true estimate of zinc deficiency in pregnancy in various populations. However, it is possible that mild to moderate deficiency (as assessed by available indicators) may be common in the developing world. Animal experiments indicate that zinc deficiency can result in adverse maternal and fetal consequences. Human data, particularly from prenatal zinc supplementation trials, has failed to document a consistent maternal or infant benefit on evaluated outcome measures including pregnancy induced hypertension, preterm/post-term labour, premature rupture of membranes, maternal infection, postpartum haemorrhage, perinatal mortality, congenital malformations and fetal growth and gestation. Preliminary data suggests a beneficial effect of prenatal zinc supplementation on infants' neurobehavioural development and immune function (evaluated by diarrhoeal and ARI morbidity incidence in the first year of 
life). Future research should focus on these functional consequences and congenital malformations (with adequate sample sizes), and simultaneously address the safety issue, particularly in relation to micronutrient interactions. In the light of the currently available information, routine zinc supplementation can not be advocated to improve pregnancy outcome.

\section{References}

Apgar J (1968) Effect of zinc deficiency on parturition in the rat. American Journal of Physiology 215, 160-163.

Apgar J (1973) Effect of zinc repletion late in gestation on parturition in the zinc-deficient rat. Journal of Nutrition 103, 973-981.

Beach RS, Gershwin ME \& Hurley LS (1982a) Gestational zinc deprivation in mice: persistence of immunodeficiency for three generations. Science 218, 469-471.

Beach RS, Gershwin ME \& Hurley LS (1982b) The reversibility of developmental retardation following murine fetal zinc deprivation. Journal of Nutrition 112, 1169-1181.

Beach RS, Gershwin ME \& Hurley LS (1983) Persistent immunological consequences of gestational zinc deprivation. American Journal of Clinical Nutrition 38, 579-590.

Biadaioli R, Bandinelli R, Boddi V, Bonfirraro G, Fimiani R, Parretti E, La Torre P \& Chieffi O (1997) Zinc blood levels in 75 puerperal women: correlation with obstetric and neonatal complications. Minerva Ginecologica 49, 371-375.

Brenton DP, Jackson MJ \& Young A (1981) Two pregnancies in a patient with acrodermatitis enteropathica treated with zinc sulphate. Lancet ii, 500-502.

Bunce GE, Lytton F, Gunesekera B, Vessal M \& Kim C (1994) Molecular basis for abnormal parturition in zinc deficiency in rats. In Nutrient Regulation During Pregnancy, Lactation and Infant Growth, pp. 209-214 [LH Allen, J King and B Lonnerdal, editors]. New York: Plenum Press.

Campbell-Brown M, Ward RJ, Haines AP, North WRS, Abrahan R, McFayden IR, Turnland JR \& King JC (1985) Zinc and copper in Asian pregnancies - is there evidence for a nutritional deficiency. British Journal of Obstetrics and Gynaecology 92, 875-885.

Caulfield LE, Zavaleta N, Shankar AJ \& Merialdi M (1998) Potential contribution of maternal zinc supplementation during pregnancy to maternal and child survival. American Journal of Clinical Nutrition 68 (suppl), 499S-508S.

Caulfield LE, Zavaleta N \& Figueroa A (1999a) Adding zinc to prenatal iron and folate supplements improves maternal and neonatal zinc status in a Peruvian population. American Journal of Clinical Nutrition 69, 1257-1263.

Caulfield LE, Zavaleta N, Figueroa A \& Leon Z (1999b) Maternal zinc supplementation does not affect size at birth or pregnancy duration in Peru. Journal of Nutrition 129, 1563-1568.

Cavdar AO, Bahceci M, Akar N, Erten J \& Yavuz H (1991) Effect of zinc supplementation in a Turkish woman with two previous anencephalic infants. Gynaecologic and Obstetric Investigation 32, 123-125.

Chandra RK \& Au B (1980) Single nutrient deficiency and cell mediated immune responses. I. Zinc. American Journal of Clinical Nutrition 33, 736-738.

Cherry FF, Bennett EA, Bazzano GS, Johnson LK, Fosmire GJ \& Batson HK (1981) Plasma zinc in hypertension/toxaemia and other reproductive variables in adolescent pregnancy. American Journal of Clinical Nutrition 34, 2367-2375.

Cherry FF, Sandstead HH, Rojas P, Johnson LK, Baston HK \& Wang XB (1989) Adolescent pregnancy: associations among body weight, zinc nutriture and pregnancy outcome. American Journal of Clinical Nutrition 50, 945-954.

Christian P \& Wesl KP Jr (1998) Interactions between zinc and vitamin A: an update. American Journal of Clinical Nutrition 68 (suppl.), 435S-441S.

Cunnane SC (1982) Fetal mortality in moderately zinc deficient rats is strictly related to the process of parturition: effect of maternal essential fatty acid supplementation. British Journal of Nutrition 47, 495-504.

Dreosti IE, Manuel SJ, Buckley RA, Fraser FJ \& Record IR (1981) The effect of late prenatal and/or early postnatal zinc deficiency on the development and some biochemical aspects of the cerebellum and hippocampus in rats. Life Sciences $\mathbf{2 8}$, 2133-2141.

Dreosti IE \& MacLennan A (1990) Maternal plasma zinc levels and first trimester abortion. Early Human Development 21, $141-142$.

Dura-Trave T, Puig-Abuli M, Monreal I \& Villa-Elizaga I (1984) Relation between maternal plasmatic zinc levels and uterine contractility. Gynaecologic and Obstetric Investigation 17, 247-251.

Frederickson CJ \& Danscher G (1990) Zinc-containing neurons in hippocampus and related CNS structures. Progress in Brain Research 83, 71-84.

Garg HK, Singhal KC \& Arshad Z (1993) A study of the effect of oral zinc supplementation during pregnancy on pregnancy outcome. Indian Journal of Physiology and Pharmacology 37, 276-284.

Garg HK, Singhal KC \& Arshad Z (1994) Effect of oral zinc supplementation on copper and haemoglobin levels in pregnant women. Indian Journal of Physiology and Pharmacology 38, 272-276.

George SS, Swaminathan S, Kanagasabapathy AS \& Seshadri L (1998) Maternal zinc indices and small babies. National Medical Journal of India 11, 120-121.

Goldenberg RL, Tamura T, Neggers Y, Cooper RL, Johnston KE, Du Bard MB \& Hauth JC (1995) The effect of zinc supplementation on pregnancy outcome. Journal of American Medical Association 274, 463-468.

Golub M, Gershwin ME, Hurley LS, Saito WY \& Hendrickx AG (1984a) Studies on marginal zinc deprivation in rhesus monkeys: IV. Growth of infants in the first year of life. American Journal of Clinical Nutrition 40, 1192-1202.

Golub MS, Gershwin ME, Hurley LS, Baly Dl \& Hendrickx AG (1984b) Studies on marginal zinc deprivation in rhesus monkeys: II. Pregnancy outcome. American Journal of Clinical Nutrition 39, 879-887.

Golub MS, Gershwin ME, Hurley LS, Hendrickx AG \& Saito WY (1985) Studies on marginal zinc deprivation in rhesus monkeys: infant behaviour. American Journal of Clinical Nutrition 42, 1229-1239.

Golub MS, Gershwin ME, Hurley LS \& Hendrickx AG (1988) Studies on marginal zinc deprivation in rhesus monkeys: VIII. Effects on early adolescence. American Journal of Clinical Nutrition 47, 1046-1051.

Golub MS, Tarantel AF, Gershwin ME, Keen CL, Hendrickx AG \& Lonnerdal B (1992) Ultrasound evaluation of fetuses of zincdeprived monkeys (Macaca mulatta). American Journal of Clinical Nutrition 55, 734-740.

Golub M, Keen CL, Gershwin ME \& Hendrickx AG (1995) Developmental zinc deficiency and behaviour. Journal of Nutrition 125, 2263S-2271S.

Halsted JA (1973) Zinc deficiency and congenital malformation. Lancet i, 1323.

Hambidge KM, Neldner KH \& Walravens PA (1975) Zinc, acrodermatitis enteropathica and congenital malformation. Lancet i, 577-578. 
Howell GA, Welch MG \& Frederickson CJ (1984) Stimulation induced uptake and release of zinc in hippocampal slices. Nature 308, 736-738.

Hunt IF, Murphy NJ, Cleaver AE, Faraji B, Swendseid ME, Coulson AH, Clark VA, Laine N, Daviis CA \& Smith JC (1983) Zinc supplementation during pregnancy: zinc concentration of serum and hair from low-income women of Mexican descent. American Journal of Clinical Nutrition 37, 572-582.

Hunt IF, Murphy NJ, Cleaver AE, Faraji B, Swendseid ME, Coulson AH, Clark VA, Browdy BL, Cabalum MT \& Smith JC (1984) Zinc supplementation during pregnancy: effects on selected blood constituents and on progress and outcome of pregnancy in low-income women of Mexican descent American Journal of Clinical Nutrition 40, 508-521.

Hunt IF, Murphy NJ, Cleaver AE, Faraji B, Swendseid ME, Browdy BL, Coulson AH, Settlage RH \& Smith JC (1985) Zinc supplementation during pregnancy in low income teenagers of Mexican descent: effects on selected blood constituents and on progress and outcome of pregnancy. American Journal of Clinical Nutrition 42, 815-828.

Hurley LS \& Swenerton H (1966) Congenital malformations resulting from zinc deficiency in rats. Proceedings of the Society for Experimental Biology and Medicine 123, 692-696.

Jameson S (1976) Effects of zinc deficiency in human reproduction. Acta Medica Scandinavica Supplementum 593, 4-89.

Jameson S (1993) Zinc status in pregnancy: the effect of zinc therapy on perinatal mortality, prematurity and placental ablation. Annals of New York Academy of Sciences 678, $178-192$.

Jonsson B, Hauge B, Larsen MF \& Hald F (1996) Zinc supplementation during pregnancy: a double blind randomised controlled trial. Acta Obstetricia et Gynaecologica Scandinavica 75, 725-729.

Keen CL, Taubeneek MW, Daston GP, Rogers JM \& Gershwin ME (1993) Primary and secondary zinc deficiency as factors underlying abnormal CNS development. Annals of New York Academy of Sciences 678, 37-47.

Kiilholma P, Gronroos M, Erkkola R, Pakarinan P \& Nanto V (1984) The role of calcium, copper, iron and zinc in preterm delivery and premature rupture of fetal membranes. Gynaecologic and Obstetric Investigation 17, 194-201.

Kirksey A, Rahmanifar A, Wachs TD, McCabe GP, Bassily NS, Bishry Z, Galal OM, Harrison GG \& Jerome NW (1991) Determinants of pregnancy outcome and newborn behaviour of a semirural Egyptian population. American Journal of Clinical Nutrition 54, 657-667.

Kirskey A, Wachs TD, Yunis F, Srinath U, Rahmanifar A, Mc Cabe GB, Galal OM, Harrison GG \& Jerome NW (1994) Relation of maternal zinc nutriture to pregnancy outcome and infant development in an Egyptian village. American Journal of Clinical Nutrition 60, 782-792.

Kynast G \& Saling E (1986) Effect of oral zinc application during pregnancy. Gynaecologic and Obstetric Investigation $\mathbf{2 1}$ $117-123$.

Lao TT, Chin RKH, Mak YT, Swaminathan R \& Lam YM (1990) Plasma and erythrocyte zinc and birth weight in pre-eclamptic pregnancies. Archives of Gynaecology and Obstetrics 247, 167-171.

Lazebnik N, Kuhnert BR, Kuhnert PM \& Thompson KL (1988) Zinc status, pregnancy complications and labour abnormalities. American Journal of Obstetrics and Gynaecology 158, $161-166$.

Lehti KK (1989) Iron, folic acid and zinc intakes and status of low socioeconomic pregnant and lactating Amazonian women. European Journal of Clinical Nutrition 43, 505-513.

Mahomed K, James DK, Golding J \& McCabek (1989) Zinc supplementation during pregnancy: a double blind randomised controlled trial. British Medical Journal 299, 826-830.

Mahomed K (1998) Zinc supplementation in pregnancy. In Pregnancy and Childbirth Module of the Cochrane Database of Systematic Reviews, Issue I [JP Neilson, CA Crowther, ED Hodnett and GJ Hofmeyr, editors]. Oxford, United Kingdom: The Cochrane Collaboration.

Merialdi M, Caulfield LE, Zavaleta N, Figueroa A \& Di Pietro JA (1999) Adding zinc to prenatal iron and folate tablets improves foetal neurobehavior development. American Journal of Obstetrics and Gynaecology 180, 483-490.

Miller ER, Luecke RW, Ullrey DE, Blatzer BV, Bradley BL \& Holfer SA (1968) Biochemical skeleton and allometric changes due to zinc deficiency in the baby pig. Journal of Nutrition 95, 278-286.

Morley JE, Gordon J \& Herschman JM (1980) Zinc deficiency, chronic starvation and hypothalamic-pituitary-thyroid function. American Journal of Clinical Nutrition 33, 1767-1770.

National Research Council. (1989) Recommended Dietary Allowance 10th edn. Washington DC: National Academy Press.

Olson DM, Mijovic JE \& Sadowsky DW (1995) Control of human parturition. Seminars in Perinatology 19, 52-63.

Ortega RM, Andres P, Martinez RM, Lopez-Sobaler AM \& Quintas ME (1997) Zinc levels in maternal milk: the influence of nutritional status with respect to zinc during the third trimester of pregnancy. European Journal of Clinical Nutrition 51, 253-258.

Osendarp SJM, vaan Raaij JMA, Arifeen SE, Wahed MA, Baqui AH \& Fuchs GJ (2000) A randomised, placebocontrolled trial of the effect of zinc supplementation during pregnancy on pregnancy outcome in Bangladeshi urban poor. American Journal of Clinical Nutrition 71, 114-119.

Parr RM (1996) Assessment of dietary intakes. In Trace Elements in Human Nutrition and Health, pp. 265-288. Geneva: World Health Organization.

Prema K (1980) Predictive value of serum copper and zinc in normal and abnormal pregnancy. Indian Journal of Medical Research 71, 554-560.

Robertson JS, Heywood B \& Atkinson SM (1991) Zinc supplementation during pregnancy. Journal of Public Health Medicine 13, 227-229.

Ross SM, Nel E \& Naeye R (1985) Differing effects of low and high bulk maternal dietary supplements during pregnancy. Early Human Development 10, 295-302.

Roungsipragarn R, Borirug S \& Herabutya Y (1999) Plasma zinc level and intrauterine growth retardation: a study in pregnant women in Ramathibodi Hospital. Journal of the Medical Association of Thailand 82, 178-181.

Sandstead HH (1985) Zinc: essentiality for brain development and function. Nutrition Reviews 43, 129-137.

Sandstrom B, Cederblad A, Lindblad B \& Lonnerdal B (1994) Acrodermatitis enteropathica, zinc metabolism, copper status and immune function. Archives of Paediatric and Adolescent Medicine 148, 980-985.

Scholl TO, Hediger ML, Scholl JJ, Fischer RL \& Khuo CS (1993) Low zinc intake during pregnancy: its association with preterm and very preterm delivery. American Journal of Epidemiology 137, 1115-1124.

Seth V \& Beotra A (1986) Malnutrition and immune system. Indian Paediatrics 23, 277-302.

Sever LE (1973) Zinc deficiency in man. Lancet $\mathbf{i}, 887$.

Shankar AH \& Prasad AS (1998) Zinc and immune functions: the biological basis of altered resistance to infection. American Journal of Clinical Nutrition 68 (suppl.), 447S-463S.

Sikorski S, Juszkiewicz T \& Paszkowski T (1990) Zinc status in women with premature rupture of membranes at term. Obstetrics \& Gynaecology 76, 675-677. 
Simmer K, Lort-Phillips L, James C \& Thompson RPH (1991) A double blind trial of zinc supplementation in pregnancy. European Journal of Clinical Nutrition 45, 139-144.

Stoll C, Dolt B, Alembik Y \& Koehl C (1999) Maternal trace elements, vitamin B12, vitamin A, folic acid and fetal malformations. Reproductive Toxicology 13, 53-57.

Tamura T \& Goldenberg RL (1996) Zinc nutriture and pregnancy outcome. Nutrition Research 16, 139-181.

Tamura T, Goldenberg RL, Johnston KE, Cliver SP \& Hoffman HJ (1997) Serum concentrations of zinc, folate, vitamin A and E, and proteins, and their relationships to pregnancy outcome. Acta Obstetricia et Gynaecologica Scandinavica. Supplement 165, 63-70.

Tamura T, Goldenberg RL, Johnston KE \& DuBard M (2000)
Maternal plasma zinc concentrations and pregnancy outcome. American Journal of Clinical Nutrition 71, 109-113.

Vallee BL \& Falchuk KH (1993) The biochemical basis of zinc physiology. Physiological Reviews 73, 79-118.

Velie EM, Block G, Shaw GM, Samuels GJ, Scheffer DM \& Kulldoff M (1999) Maternal supplemental and dietary zinc intake and the occurrence of neural tube defects in California. American Journal of Epidemiology 150, 605-616.

Whittaker P (1998) Iron and zinc interactions in humans. American Journal of Clinical Nutrition 68 (suppl.), 442S-446S.

Zimmerman AW, Dunhan BS, Nochimson DJ, Kaplan BH, Clive JM \& Kunkel SL (1984) Zinc transport in pregnancy. American Journal of Obstetrics and Gynaecology 149, 523529. 